\title{
Marine bile natural products as agonists of the TGR5 receptor -
}

\section{Supporting Information}

\author{
Christopher Halkias ${ }^{\dagger}$, William G. Darby ${ }^{\dagger}$, Bryce N. Feltis ${ }^{\dagger}$, Peter Mclntyre $^{\dagger \ddagger}$, \\ Theodore A. Macrides ${ }^{\dagger}$, Paul F.A. Wright ${ }^{\dagger} *$
}

${ }^{\dagger}$ School of Health and Biomedical Sciences, RMIT University, Bundoora, Victoria 3083, Australia

${ }^{\ddagger}$ The Florey Institute of Neuroscience and Mental Health, Parkville, Victoria 3052, Australia

*Corresponding Author:

Assoc. Prof. Paul F. A. Wright

School of Health and Biomedical Sciences

RMIT University

PO Box 71

Bundoora 3083

Victoria, Australia

Tel: +61 399256512

E-mail: paul.wright@rmit.edu.au

\section{TABLE OF CONTENTS}

Figure S1: Effects of 0.5\% (v/v) DMSO on HEK293-TGR5 cells after $2.5 \mathrm{~h}$ of exposure

Figure S2: Effects of $1 \mathrm{mM}$ UDCA (3) compared to 0.5\% DMSO vehicle on HEK293 and HEK293-TGR5 cells, in the absence of extracellular calcium 




Figure S1: Effects of 0.5\% (v/v) DMSO on HEK293-TGR5 cells after $2.5 \mathrm{~h}$ of exposure.

DMSO at $0.5 \%(\mathrm{v} / \mathrm{v})$ did not induce cytotoxicity upon HEK293-TGR5 cells, confirming its suitability as the vehicle for the test compounds in this study. Data expressed as \% viability of untreated control (untreated HEK293-TGR5 cells; mean \pm SEM of triplicate samples; $n=4$ experiments). 


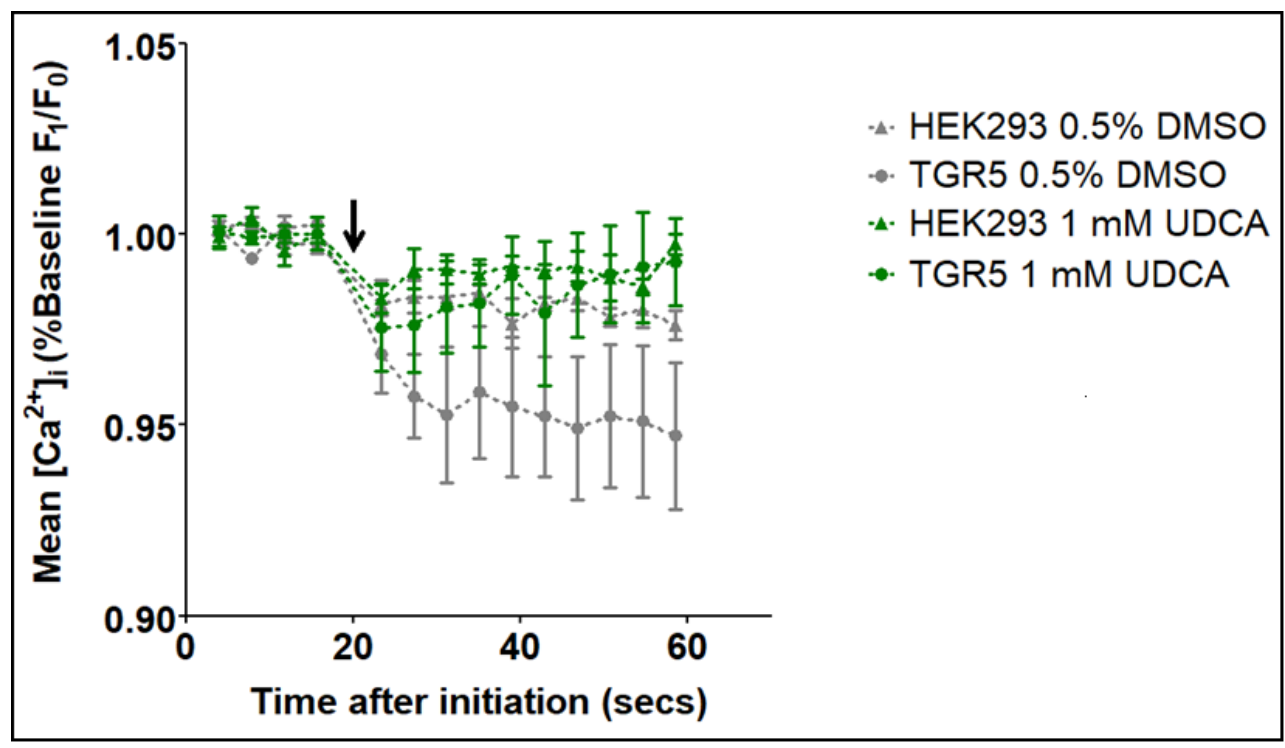

Figure S2: Effects of $1 \mathrm{mM}$ UDCA (3) compared to 0.5\% DMSO vehicle on HEK293 and HEK293-TGR5 cells, in the absence of extracellular calcium. $1 \mathrm{mM} 3$ was added to the incubation after approximately 20 seconds, as indicated by the black arrow. The results shown are mean ratio change in fluorescence from baseline $\left[\mathrm{Ca}^{2+}\right]_{\mathrm{i}}$ levels over $\sim 70 \mathrm{~s}$ exposure time; without extracellular $\mathrm{Ca}^{2+}$ (mean \pm SEM of quadruplicate samples; $\mathrm{n}=4$ experiments). 